
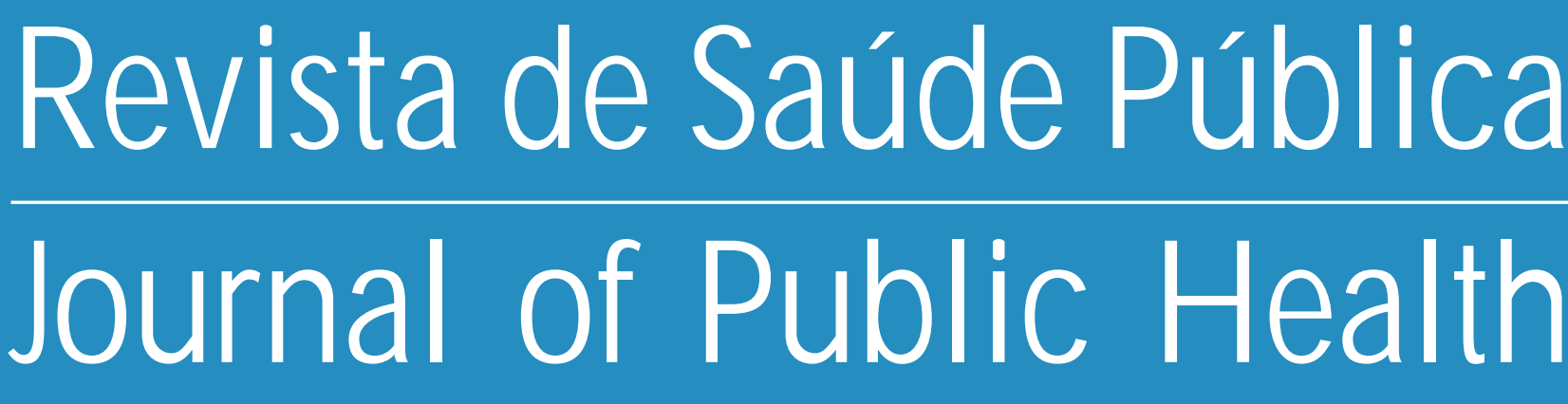

\title{
A prostituição infantil sob a ótica da sociedade e da saúde
}

Child prostitution from the point of view of society and as a health question

\section{Romeu Gomes, Maria Cecília de Souza Minayo e Helena Amaral da Fontoura}

Instituto Fernandes Figueira da Fundação O swaldo Cruz (FIO CRUZ). Rio de Janeiro, RJ - Brasil (RG); Fundação O swaldo Cruz. Rio de Janeiro, RJ - Brasil (M CSM ); Faculdade de Educação da Universidade Federal Fluminense. Niterói, RJ - Brasil (HAF) 


\section{A prostituição infantil sob a ótica da sociedade e da saúde Child prostitution from the point of view of society and as a health question}

\section{Romeu Gomes, Maria Cecília de Souza Minayo e Helena Amaral da Fontoura}

Instituto Fernandes Figueira da Fundação O swaldo Cruz (FIO CRU Z). Rio de Janeiro, RJ - Brasil (RG); Fundação O swaldo Cruz. Rio de Janeiro, RJ - Brasil (MCSM); Faculdade de Educação da Universidade Federal Fluminense. Niterói, RJ - Brasil (HAF)

\section{Descritores}

Prostituição infantil.

Problemas sociais.

Saúde infantil [Saúde pública].

\section{Resumo}

Objetivo

Analisar as representações sociais e as relações estruturais em torno da prostituição infantil, presentes nos depoimentos prestados à Comissão Parlamentar de Inquérito que tratou dessa problemática.

\section{Métodos}

Com base em metodologia qualitativa, a análise procurou identificar os núcleos de sentido presentes nos depoimentos.

\section{Resultados}

São apresentados dados das regiões do Brasil acerca do objeto de estudo. Focaliza-se a visão do cenário social em torno dos dados, expressando determinações histórico-culturais relacionadas à temática.

\section{Conclusão}

A prostituição infanto-juvenil está calcada na comercialização do corpo como coerção ou escravidão ou para atender às necessidades básicas de sobrevivência. Destaca-se ainda a necessidade de ações sociais, aí incluindo as da saúde coletiva, para que o tema não fique apenas nas hipérboles dos discursos e dos números; transforme a fala em atitude.

\begin{abstract}

\section{Objective}

The social representations and the structural relationships related to child prostitution, as presented in the depositions made before of the Parliamentary Comission Inquiry dealing with the problem are analyzed.
\end{abstract}

Methods

On the basis of qualitative methodology, the analysis attempts to identify the units of meaning present in the depositions. 


\section{Results}

Data on the subject are presented by region. A vision of the social scene is built up on the basis of the data such as to breing out the related historical and cultural determining factors.

\section{Conclusion}

The child juvenile prostitution is based on the commercialization of the body as coercion or slavery is seen as a means of meeting the basis needs of survival. The need for social action is brought out, including that of collective health, so that the theme does not serve only the amposes of rhetoric on statistics, because in calls for decisive action.

\section{INTRO DUÇÃO}

No presente trabalho, a expressão prostituição infantil, com base em Saffioti ${ }^{12}$ (1989), é entendida a partir de duas abordagens: uma que se entrecruza com o conceito de exploração econômica e outra que se refere à obtenção de prazer, com prejuízo de saúde mental de quem está sendo explorado. Essa expressão não está relacionada apenas a crianças; ela serve também para adolescentes que, mesmo não tendo ainda uma consciência sobre a sua sexualidade e sobre o seu corpo, são levados a se prostituírem por diferentes motivos. Essa discussão conceitual pode ser melhor aprofundada nas publicações de Gomes ${ }^{6,7}(1994,1996)$.

Apesar de ter havido ampla discussão sobre a prostituição infantil, percebe-se que, em termos de resultados de pesquisas publicados, ainda pouco se tem produzido. Portanto, para se abordar o assunto, tem-se que recorrer a referenciais dos estudos sobre a prostituição em geral. Neste texto foram feitas considerações acerca da prostituição enquanto saber médico, a partir de estudos baseados em teses de medicina do século XIX, produzidas na cidade do Rio de Janeiro. Apoiados na análise de Gomes ${ }^{6,7}$, percebe-se que, na produção médica do século passado, a prostituição revela-se como: (a) perigo físico enquanto causa de doenças, com destaque para a sífilis; (b) perigo moral, uma vez que para esse saber a prostituição poderia ser um exemplo pernicioso para as moças; (c) fato natural e social porque, além de ser prática presente em todos os países e em eras mais primitivas, estaria ligada ao organismo humano, permitindo que o instinto sexual se realize, promovendo uma entrega ao desejo arrebatador.

Com base na literatura, observa-se que, no saber médico que atravessa o fim do século passado para o início deste, a prostituição associou-se às doenças venéreas, permeada por estigmas. Com o surgimento da AIDS (síndrome da imunodeficiência adquirida), Chacón ${ }^{4}$ (1992) observa que alguns médicos passaram a incluir a prostituição nos chamados grupos de risco de transmissão dessa doença. Nesse contexto, ainda está presente o esquema de racionalidade que faz conexão entre prostituta e gozo/doença/morte.

Especificamente sobre prostituição infantil, Gomes $^{6}$ (1994) apresenta um levantamento bibliográfico, remetendo o assunto para o âmbito da saúde pública, na qual foram fundamentadas as reflexões sobre o tema. Nesse levantamento, são identificados 12 títulos bibliográficos que, em geral, se referem a artigos ou seções de livros. Constatando a existência de escasso material bibliográfico, em língua portuguesa, relativo à pesquisa de campo sobre o assunto, observa-se que a produção analisada aponta para o fato de a prostituição infantil feminina cada vez mais se configurar como uma cruel realidade no seio da infância brasileira, demandando, pelos comprometimentos mentais e físicos que acarreta, atenção por parte da saúde pública.

Na tentativa de contribuir para o desenvolvimento dessa discussão, o presente artigo apresenta parte de uma pesquisa que aborda a relação entre prostituição infantil feminina, processo saúde-doença e violência (CLAVES ${ }^{5}$, 1994), patrocinada pela Organização Panamericana de Saúde (OPS) e desenvolvida pelo Centro Latino-Americano de Estudos de Violência e Saúde "Jorge Careli” (CLAVES) da Fundação Oswaldo Cruz. Gomes ${ }^{7}$ (1996) retomou esse trabalho, ampliando a sua análise e buscando um aprofundamento teórico e metodológico sobre a temática e o seu cenário social. 


\section{MÉTO DOS}

Foram realizadas análises das representações sociais e das relações estruturais em torno de seu objeto de estudo. Ao longo de seu processo, a investigação que lhe deu origem levou à análise de documentos, à observação participante em instituições voltadas para meninas que viviam na rua e à realização de entrevistas semi-estruturadas com meninas e educadores de rua.

$\mathrm{O}$ presente artigo especificamente apresenta um recorte dos estudos realizados por Gomes ${ }^{6,7}$. Nesse sentido, tem como material de análise os depoimentos prestados à Comissão Parlamentar de Inquérito (CPI) instaurada pela Câmara Federal dos Deputados, com 13 deputados-titulares de diferentes partidos e igual número de suplentes, que objetivou apurar responsabilidades pela exploração e prostituição infanto-juvenil, cujo funcionamento ocorreu no período de maio de 1993 a março de 1994.

As pessoas que prestaram depoimento nas sessões da CPI representavam instituições governamentais e não governamentais, e grupos, destacando os seguintes depoentes: membros de grupos ligados à defesa dos direitos da criança; voluntários e profissionais que trabalhavam com crianças sexualmente exploradas e/ou meninos e meninas que vivem na rua; líderes religiosos; jornalistas e radialistas; juiízes e promotores públicos; policiais; representantes de ministérios e secretarias de estados; membros de órgãos públicos internacionais, a exemplo do UNICEF (Fundo das Nações Unidas para a Infância).

Foram consultadas as notas taquigráficas de 22 sessões da CPI realizadas no período de junho de 1993 a março de 1994, perfazendo 87 depoimentos. Quando se procedeu à análise desse material, o relatório da CPI não havia sido concluído. Com base neste fato, as considerações aqui constantes estão centradas nas falas de depoentes e não no pensamento oficial da CPI.

Por se tratar de uma Comissão Parlamentar, entendese que a compreensão da fala, aí expressa, traduz de forma privilegiada o campo de preocupações, de estereótipos, de preconceitos e também de busca de possíveis soluções. No estudo desses depoimentos, focaliza-se principalmente as representações sociais da prostituição infantil. Assim como Adam e Herzlich ${ }^{1}$ (1994), acredita-se que, para se ter acesso às representações, é necessário compreender que as falas apoiam-se em noções, símbolos e esquemas de referências interiorizados, relacionados às suas origens sociais e culturais. Ou de acordo com Bourdieu² (1972) as falas revelam "habitus" que são expressões culturais de grupos e classes, e de seus costumes fortemente enraizados que permitem a interação. Portanto, a fala, segundo Habermas $^{8}$ (1987), é ao mesmo tempo uma expressão, uma representação e uma interação.

A técnica de análise dos depoimentos baseia-se na proposta de Minayo ${ }^{10}$ (1992), que procurou integrar aspectos da análise temática de $\operatorname{Bardin}^{2}$ (1979) e princípios da concepção de Habermas ${ }^{8}$ (1987). A técnica de análise temática "consiste em descobrir os 'núcleos de sentido' que compõem a comunicação e cuja presença, ou freqüência de aparição podem significar alguma coisa para o objetivo analítico escolhido." (Bardin², 1979: 105). Por núcleo de sentido entende-se o conjunto de categorias empíricas que povoam o campo semântico definidor do conceito, das causas, das associações e da significância do fenômeno prostituição infantil. A análise dos núcleos de sentido ocorreu através de um movimento dialético estabelecido entre a interpretação dos textos e o contexto sociocultural em que se produziu a fala (Habermas $\left.{ }^{8}, 1987\right)$.

Inicialmente foi feita uma leitura vertical em cada depoimento, procurando apreender não só o seu conteúdo como também a sua lógica. Em seguida, através de leituras horizontais, perfilando os documentos um ao lado do outro, identificaram-se características regionais. Após este momento, foi feita nova leitura horizontal, estabelecendo confronto das conclusões regionais e buscando núcleos de sentidos para constituir temáticas de análise. Situando a fala no contexto sociocultural, realizouse a análise final.

A presente análise volta-se mais para a caracterização do problema do que para sua extensão. Sobre a quantificação da problemática, mesmo que esta se constituísse em meta desta análise, não poderia ser adequadamente dimensionada porque os dados apresentados são incompletos em alguns casos, insuficientes em outros e inexistentes para certos aspectos. Madeira9 (1997) observa que a trajetória das denúncias da prostituição infantil feminina vai da superestimação de valores à estigmatização e apresenta série de dados de denúncias sobre a problemática que, ao serem submetidos a um cuidadoso rastreamento, não apresentaram confiabilidade por não se ter chegado à fonte que os teria produzidos.

Acredita-se que a atenção da saúde pública à prostituição infantil feminina não pode ser vista apenas como uma demanda da magnitude do problema, que tem se configurado de uma forma bastante imprecisa, mas sim a partir de sua relevância social e humana e sua complexidade que trazem, entre outras conseqüências, comprometimento no campo do desenvolvimento e crescimento físico, mental e social de crianças e adolescentes. O problema em si é importante, independentemente da dimensão que adquire, embora empiricamente se possa constatar a extensão desse processo pelas várias regiões do País.

\section{RESU LTADO S E DISCUSSÃO}

Através da análise dos depoimentos, logo de início, constatou-se que a prostituição infantil feminina configura-se de uma forma distinta nas regiões brasileiras. Entretanto, aprofundando mais a leitura, percebe-se que há um cenário comum que perpassa as diferenças regionais. Frente a essa constatação, optou-se pela seguinte forma de tratamento aos dados: (1) apresentar as diferentes configurações regi- 
onais para que se pudesse destacar as características que a problemática assume em cada local, segundo a ótica dos depoentes; e (2) discutir os núcleos de sentidos identificados nos diferentes depoimentos, procurando compor eixos de discussão que atravessam todas as regiões, para subsidiar a formulação de políticas e procedimentos no campo da saúde.

\section{As Configurações Regionais da Prostituição sob a Ótica da CPI}

Em geral, áreas do Centro-Oeste e do Norte se misturam na prática do tráfico de meninas recrutadas para a prática da prostituição, tendo como capital desta rota Itaituba, Município do Pará. Mas, nessas regiões, os problemas não são uniformes em todos os locais. Há diferenças nas áreas de garimpos, comparadas ao agenciamento da prostituição infantojuvenil das cidades, como Belém e Manaus, no Norte, e Brasília, no Centro-Oeste. No interior, nos centros urbanos também a situação apresenta várias modalidades. $\mathrm{O}$ aliciamento para a prostituição bem como a sua manutenção oscila entre o requinte, como é o caso dos programas de hotéis para clientes importantes, financeira, social ou politicamente, e o ambiente das meninas pobres, sobretudo das que vivem na rua, exploradas financeira e sexualmente por policiais e pessoas que vivem ou transitam nesses espaços públicos.

Na Região Nordeste foram constatadas duas realidades. Uma delas se refere ao fato de meninas que vivem na rua recorrerem à prostituição ou a ela se submeterem como forma de sobrevivência. A outra diz respeito ao agenciamento de crianças e adolescentes, em estabelecimentos privados, para a comercialização do sexo. No âmbito da comercialização, há praticamente em todo Nordeste uma predominância de turismo sexual com, pelo menos, duas formas de agenciamento. A mais comum, em cidades como Natal, Fortaleza e Recife, é a promoção de pacotes de turismo que incluem as meninas como atração sexual. Donos de hotéis, táxis, barracas das praias e de boates formam uma rede organizada em torno desse negócio rentável. Há relatos que também apontam a existência de tráfico de adolescentes para o exterior, com destino à prostituição.

Em relação ao Sul, destacam-se os depoimentos relativos aos Estados do Rio Grande do Sul e de Santa Catarina, apontando também a existência de gangues e quadrilhas especializadas em traficar e prostituir meninas. Há casos em que meninas são vendidas por 50 a 100 dólares cada uma. Entre as formas de aliciamento no interior dos Estados dos Sul, ressaltam-se as seguintes: (a) gigolôs, escolhido como símbolo da gangue, passava, no interior, por inofensivo vendedor de bonecas e bichinhos de pelúcia, expostos em praça pública, funcionando como chamariz; (b) anúncio de programa de rádio, chamado "Hora do Recado", oferecendo emprego e escola, mas na realidade servindo de recrutamento de meninas para agenciadores; (c) motoristas de táxis que, com promessas de emprego, recrutam as crianças nas casas do pai e levando-as para um prostíbulo de beira de estrada, fazendo eles próprios, no caminho, a iniciação sexual; (c) gigolôs que pegam jovens prostituídas e as levam para o local onde a safra agrícola for melhor.

Na Região Sudeste, ressaltam-se os relatos do Rio de Janeiro e São Paulo. Na cidade do Rio de Janeiro, a situação encontrada foi a seguinte: a) foi a única área onde os depoimentos nomearam a prostituição infantil masculina, sendo basicamente de natureza homossexual, com "michês" oriundos de várias classes sociais; b) apresenta situações semelhantes às outras regiões, onde existem explorações de turismo sexual e por clientes locais; c) mencionam-se casos de meninas que vivem nas ruas e para sobreviverem trocam favores sexuais, sem elas se considerarem prostitutas; d) assinala-se a presença marcante de pseudo agências de modelos, camuflando a exploração sexual de meninas e adolescentes; e) registrado, pela gravidade da denúncia, o caso de uma diretora de CIEP (Centro Integrado de Educação Popular) que organizou um álbum de fotografias de estudantes, encaminhando-o a um motel para a escolha de clientes.

No que se refere à situação de São Paulo, existem menções de casos de crianças e adolescentes que vivem na rua e sofrem violências sexuais, principalmente por parte de policiais, assim como de outras que caem nas mãos dos cafetões ou cafetinas. Algumas delas usam drogas, crack na maioria das vezes ou são usadas por traficantes para passar as drogas para os clientes. Outras, que chegam com caminhoneiros fugindo de casa ou com o sonho de emprego, são presas fáceis para os agenciadores. A polêmica que se estabelece entre meninas que vivem na rua e prostituição infanto-juvenil também é objeto de discussão nesse Estado. 
Em síntese, a prostituição infanto-juvenil configura-se de forma diferente entre e intra região. No Norte e no Centro-Oeste, o tráfico de escravas nas áreas do garimpo é uma tônica; o turismo sexual destaca-se no Nordeste, no Sudeste a discussão sobre meninas que vivem na rua surge junto com a discussão da prostituição infanto-juvenil; e no Sul, a base da exploração está no aliciamento das crianças e adolescentes do interior, a partir do uso de informações falsas e de abuso da ingenuidade dos pais. Mas esta síntese das configurações revela apenas fatos que aparecem, enquanto figuras, num primeiro plano.

\section{Núcleos de Sentido de uma Realidade Polissêmica}

A pergunta chave desta análise é: que questões centrais o conjunto de depoimentos da CPI revela sobre o imaginário social e o contexto nacional, influenciando comportamentos, atitudes e práticas, sobre o tema da prostituição infantil? Essas questões estão analisadas como núcleos de sentido extraídos das proposições que compuseram o discurso coletivo na Comissão, expostos dentro de três grandes categorias de pensamento:

a) explicações causais macro e microssociais da prostituição infantil;

b) associações freqüentes entre prostituição, pobreza, drogas, doenças, violência e vida nas ruas;

c ) formas de dimensionamento do problema.

Entende-se que causas, associações e magnitude constituem as grandes categorias, em torno das quais o discurso e as práticas da sociedade sobre a prostituição infantil são construídos, perpassando as formas sociais e individuais de sua explicação.

Explicações causais da prostituição infantil - As representações das causas nos depoimentos da CPI oscilam entre a busca de explicações estruturais e a culpabilização dos indivíduos. No âmbito das análises de cunho macrossocial estão o reconhecimento das desigualdades de classe, das situações de extrema pobreza e de exclusão como pano de fundo do entendimento. Em alguns depoimentos são apresentados recortes de gênero mediando as relações de classe, em que o machismo, o tratamento e a formação diferenciada a que têm acesso meninos e meninas são apontados como fortes componentes cultu- rais presentes na problemática da prostituição infantil. Esses depoimentos, em parte, reforçam a idéia de Saffioti ${ }^{12}$ (1989) de que a existência de meninas prostituídas explica-se pelo fato de a sociedade ocidental ser "androcêntrica" e "adultocêntrica", nela se tornando visível o poder do homem e o poder do adulto. Alguns dos depoentes assinalam o relevante aspecto da cultura patriarcal que, dentre outras questões, promove a expulsão de casa de meninas precocemente grávidas, como agravante da situação estudada.

Do ponto de vista da culpabilização dos indivíduos, os depoimentos apontam vários atores específicos com papéis e responsabilidades diferenciadas. De um lado estão os pais que ora aparecem premidos por extremas necessidades materiais, quando a "venda do corpo" da filha ou a "venda da filha" se lhes afigura como alternativa de sobrevivência imediata da família. De outro, são citados aqueles para quem a moral patriarcal de grande rigidez os leva a formas de educação feminina extremamente coercitivas e hierárquicas, propiciando condenação moral estrita de relações com os meninos com receios dos riscos de interações sexuais precoces. Essas atitudes moralistas e distantes acabam por provocar o seu contrário, a fuga da menina e da adolescente do controle familiar, freqüentemente a gravidez precoce e, como conseqüência, a expulsão e a perda da proteção do lar. Esses episódios reiteradamente citados, acabam, no dizer da CPI, incluindo os pais como parte do processo de prostituição infantil.

Outros atores tratados como responsáveis são os policiais, donos de boates, caminhoneiros, dentre outros. Vale a pena ressaltar o papel dos policiais, reiteradamente reconhecidos ora como agressores, ora como agentes de exploração. Enquanto agressores eles sintetizam o ideário de preconceitos e discriminações da sociedade sobre as meninas, tomando-as como "vagabundas", "perdidas" e por isso merecedoras de maus tratos, espancamentos e intimidações. Como agentes, muitos depoimentos os apresentam como parte integrante da rede de aliciamentos, de sedução e do comércio dos corpos infantis e adolescentes. Sua ação, reconhecida como perniciosa e raramente como protetora, estende-se aos agentes educadores, buscando desmoralizá-los e desqualificar seu trabalho, dizendo que "só o fazem pelo dinheiro envolvido, pelos dólares das ONGs (Organizações não governamentais)". 
Em todos os depoimentos, o sujeito-objeto da exploração infantil, a criança ou a adolescente, aparece como vítima. Essa categoria fortemente saturada de significado é o núcleo de sentido mais problemático no discurso da CPI. Se é verdade que no caso da prostituição infantil não se pode desconhecer de forma alguma o peso das condições gerais de pobreza e miséria em que ela acontece; a influência determinante das relações patriarcais que a possibilitam e alimentam sua reprodução; o papel atualizador da dominação adultocêntrica e machista no cotidiano; não se pode, em hipótese alguma, desconhecer o status de sujeito de direitos que qualquer criança e adolescente possui. Esse sujeito, eticamente, não pode ser reduzido à condição de vítima. A certeza dessa convicção se traduz, no mínimo, em contar com essas meninas na definição de sua situação, para compreendê-la e superá-la. Tratar esse grupo social, já tão discriminado e alijado apenas como vítima, supõe decidir por ele seu presente e seu futuro. É preciso lembrar que, embora tenuemente, existe um grau de liberdade e de resistência a ser recuperado e explicitado nessa porção de nossa sociedade desigual e cruel, sob pena de qualquer intervenção externa tornar-se ineficaz e alienada.

As associações semânticas do conceito de prostituição infantil - $\mathrm{O}$ segundo aspecto a ser analisado é o das associações semânticas do conceito de prostituição infantil. Nos depoimentos, o problema aparece aproximado ao mesmo universo da violência, das drogas, das doenças venéreas e contagiosas e das vivências nas ruas. Nos discursos apresentados na CPI, a fala sobre os diferentes tipos de violência permeia as explicações. De um lado aparece o conceito de violência estrutural, aquela que se define pela existência e reprodução das desigualdades, exclusão social e moral, pela dominação de classe, de gênero e adultocêntrica sobre a infância. Essa aparece como pano de fundo da questão em pauta. A exploração sexual e a violência física que costuma acompanhá-la são vistas como resultantes das questões estruturais. Sobre a associação violência prostituição, observa-se, baseada em Chacón ${ }^{4}$ (1992), que o corpo menina prostituída, assim como na prostituição em geral, é um corpo silenciado. Entretanto, a partir desse silêncio escuta-se a história da violência, marcada por contradições, a exemplo das antinomias paganismo/cristianismo, desejo/transgressão, limpeza/sociedade e possibilidade/ morte.
No campo polissêmico da prostituição infantil, o problema das drogas sempre aparece, ora mitificado através de generalizações que não se fundamentam em fatos comprovados, ora enquanto complicador e parte da exploração. O universo da prostituição em geral é visto como parte do submundo social e da mesma forma, o das drogas, em que tanto as relações como os costumes e as interações como os sujeitos são considerados diferentes e da sociedade "normal". No âmbito do discurso sobre a exploração sexual infantil, as drogas são mencionadas no processo de iniciação das meninas na prostituição, como lenitivo e mitigação de sua situação de opressão e sofrimento e, também, como iniciação na rede de tráfico. A fala da CPI não vai além da constatação, não rompe o círculo da descrição do problema e das questões mais profundas que o fenômeno das drogas significa.

A prostituição infantil aparece também associada a doenças, repetindo-se o discurso do século XIX, já apontado por Gomes ${ }^{6}$ (1994). Da mesma forma que o discurso sanitário do final do século passado e início deste, a CPI aponta para os comprometimentos físicos e psicológicos da sexualidade desprotegida. A expressão dessas idéias aparece na fala do Ministro da Saúde, naquela Comissão, quando diz que as conseqüências desastrosas da prostituição infantil são: "gestação precoce e indesejada, aborto provocado, aborto espontâneo, casamentos forçados, nascimentos prematuros, traumas de parto, doenças de transmissão sexual e a própria infertilidade." Tais problemas não constituem, na prática, questões próprias do fenômeno da prostituição infantil e, ao serem associados a ela, apenas explicitam uma retórica que reproduz o discurso sanitário generalizante e estereotipado.

A violência fatal, a morte, também aparece associada, não mais através da fala médica e sim no discurso jornalístico, sendo esse um pouco mais aproximado da subjetividade das crianças e adolescentes. De um lado apontam-se as tentativas de suicídio (60\% das meninas confessam já terem tentado se matar, segundo G. Dimenstein em seu depoimento dado à CPI) por causa da rejeição social e do automenosprezo que dizem sofrer. De outro lado, o mesmo discurso aponta para a exposição às doenças transmissíveis por causa da alta rotatividade em que as meninas trabalham e pelos preconceitos brutais dos homens quando se recusam a usar preservativos, acusando-as de estarem contaminadas. 
Oúltimo núcleo de sentido associativo é o que junta como sinônimos o viver nas ruas e o ser prostituta. Intencionalmente ou não, essa relação preconceituosa contribui para o reducionismo na discussão de ambos os problemas. Vários estudos, dentre eles o de Gomes $^{7}$ (1996), partem da definição dada pelas meninas que, por circunstâncias especialmente difíceis vivem nas ruas e mostram que a questão é muito mais complexa. Primeiro porque muitas abandonam seus lares exatamente por serem, em seu interior, vítimas de abuso sexual de familiares e freqüentemente dos sucessivos companheiros de suas mães. Segundo porque elas apresentam lógica própria aos moradores de rua que, nesse espaço sui generis de vida, constróem normas e códigos de honra de convivência que, no mínimo, precisam ser entendidos a partir dessas pessoas. Por fim, porque as próprias crianças e adolescentes repudiam essa simbiose construída pelo olhar externo, alertando para o fato de que nem sempre a única alternativa à situação de miséria é a comercialização do corpo. Muitas delas inclusive fazem questão de distinguir "transar por necessidade de dinheiro" e prostituição. Portanto, a associação simples entre o incremento do número de meninas vivendo nas ruas $\mathrm{e}$ a prostituição não apenas produz cifras imprecisas e errôneas, como contribui para a reprodução de estereótipos. Dentre eles, o de que a mulher que está na rua é prostituta, e o reforçamento do estigma sobre essas pessoas que raramente escolheriam, por puro desejo, a situação em que vivem.

Formas de dimensionamento do problema - O último ponto a ser discutido é a forma como a sociedade tem dimensionado a prostituição infantil. Essa forma poderia ser resumida pela constatação do exagero dos números. Para mostrar sua indignação, a maioria dos depoentes fazem uso de estatísticas, visando a legitimar o tema dentre os grandes problemas brasileiros. Um exemplo disso são os dados apresentados pelo Ministro da Saúde, em depoimento fornecido à CPI, com base nas informações da Organização Américas Watch, segundo o qual o Brasil tem hoje 500 mil prostitutas menores de 17 anos. Tal informação é absurda, a menos que o conceito de prostituição fosse demasiado extenso e frouxo. Madeira $^{9}$ (1997) observa que esse dado é o mais recorrente nos discursos de diferentes órgãos de comunicação de massa. No entanto, segundo a autora, estudo realizado por Rosemberg ${ }^{11}$ (1993) não conseguiu chegar à fonte dessa cifra.
Outros depoimentos também se apoiaram em estimativas e percentuais inconsistentes, sem claras referências na realidade, hiperbolicamente, como se fosse necessário o exagero dos dados para provocar a comoção dos políticos e da sociedade. Na própria CPI, outros depoentes chamam atenção para o fato de que não há dados nacionais confiáveis. $\mathrm{O}$ ato de quantificar revela uma lógica presente no discurso político e popular, na busca de legitimar "cientificamente" as proposições e alertar para a gravidade dos fenômenos. Esse costume, no entanto, acaba por gerar o efeito contrário. Ou seja, alimenta a crença de que os problemas são insolúveis. E além disso, o hiperbolismo dos dados pressupõe que a importância do tema é dada pela sua extensão e menos pela sua significância social e humana.

A prostituição infantil parece não escapar desse raciocínio de magnitude dada pelos números. Ou seja, para que fosse reconhecido enquanto questão social e objeto de investimento público seria necessário que sua existência fosse reconhecida estatisticamente. Não se cogitam possibilidades de intervenções locais, sobre estruturas injustas e arcaicas, sobre costumes e relações que possam ser mapeadas, rastreadas e coibidas. Muitas vezes pequenas propostas valem mais que megaprojetos, e nesse caso específico, sem dúvida, valem.

\section{COMENTÁRIO S FINAIS}

O discurso da CPI sobre a prostituição infantil é importante por vários motivos, mas de forma particular, pelo fato do Parlamento ser a caixa de ressonância das idéias e do imaginário da própria sociedade brasileira. De um lado, aí se encontra a expressão representativa e simbólica da complexidade da própria população nacional. De outro, ele tem a capacidade de convocação dos atores sociais mais diversos que pensam e atuam frente aos problemas relevantes que discute e sobre os quais legisla.

Como seria de se esperar, os discursos aí produzidos sobre prostituição infantil não são nem homogêneos nem convergentes. São antes polissêmicos, muitas vezes contraditórios, revelando o lugar, o papel, a profissão, o envolvimento dos diferentes depoentes chamados a opinar sobre a questão. Há, no entanto, um grau de convergência quanto ao repúdio e à indignação sobre um processo que revela as entranhas de uma sociedade injusta, adultocêntrica e machista. 
Mesmo quando se tem um discurso indignado, observa-se que, na sua quase totalidade, as falas são informadas por uma perspectiva de quem olha o problema externamente, noutras palavras, a partir da ótica da filosofia da consciência que separa os sujeitos que produzem o conhecimento dos seus objetos de análise. A não ser emocionalmente, as informações produzidas não produzem significados efetivos e eficazes para a ação. Quando essa investigação foi realizada, ainda não haviam sido terminados os relatórios da CPI. Mas desde então até hoje, o único resultado alcançado foi o próprio relatório.

Por ser externo às experiências vivenciadas pelas meninas, o discurso tende a não captar a lógica interna de ação, resistência e caminhos de possibilidades, tendendo a reforçar os preconceitos já apontados como: considerar pobreza e miséria como núcleo gerador da prostituição; colocar na desagregação familiar a causa do problema; entender a droga como estando linearmente associada à exploração sexual; e apontar a doença venérea como o maior risco à saúde das crianças e adolescentes.

Se cada um desses argumentos possui seu grau de verdade e deve ser considerado para análise, seria necessário aprofundar nas determinações profundas e extensas que atuam na produção e reprodução desse fenômeno. Por outro lado, e ao contrário, é preciso partir para ações locais específicas, onde cada uma dessas meninas e adolescentes se sintam protegidas, amparadas e capazes de se anteporem ao automenosprezo a auto-estima e o respeito da sociedade. Essa ação focalizada só será efetiva se for fundada na crença da subjetividade desse segmento da população, no reconhecimento de seus direitos humanos e sociais enquanto princípio e fim de qualquer intervenção.

Do ponto de vista da saúde "stricto sensu", além obviamente de todos os cuidados de prevenção ao risco das doenças, o eixo da ação deveria ser norteado pelas necessidades de crescimento e desenvolvimento dessas meninas. Dentro da visão ampliada de saúde, também deve existir o comprometimento com ações intersetoriais que possam atingir as causas macrossociais e promover a proteção do estado e da sociedade sobre essas crianças e adolescentes.

Por tudo isso, o espaço político dado ao tema da prostituição infantil precisa transcender à catarse da "má consciência" da sociedade e representar o efetivo papel do poder público frente a esse problema social. Para isso: a) é preciso entender a prostituição infantil como a forma mais perversa de violência de gênero, expressão do poder patriarcal, segundo o qual o homem considera seu direito ter acesso ao sexo, seja sob a forma de direito adquirido através do casamento, seja sob a forma de coação física, moral e econômica. Mulher, sexualidade e dinheiro vinculam o tema da prostituição a costumes ancestrais que a vêem como mal necessário para permitir o bem da família constituída; b) existe sim uma real vinculação entre extrema pobreza e miséria material que acompanha o "cair na vida" por parte de crianças e adolescentes. No Brasil (e a CPI constatou isso) a prostituição infantil está calcada na comercialização do corpo ou como escravidão para atender a necessidades básicas de sobrevivência. Tal situação fica gritante em regiões de garimpo onde vários pais agenciam a exploração sexual. Entretanto, isso não significa que haja necessariamente uma associação entre esses aspectos porque nem sempre mulheres em situação de pobreza e miséria tornam-se prostitutas. Do ponto de vista cultural é preciso não arrefecer as denúncias, as ações indignadas, as aplicações de punições aos aliciadores, comerciantes e escravizadores. Não se pode aceitar a prostituição infantil como fenômeno decorrente do pendor de certas meninas, ou de "escolha imoral" assumida por elas individualmente, porque se está lidando com seres muito frágeis socialmente, em processo de crescimento físico e de identificação psíquica, que enquanto sujeitos de direitos, necessitam da proteção familiar e do Estado e da sociedade. 


\section{REFERÊNCIAS}

1. Adam P, Herzlich C. Sociologie de la maladie et de la médicine. Paris: Ed. Natham Université; 1994.

2. Bardin L. Análise de conteúdo. Lisboa: Edições 70; 1979.

3. Bourdie P. Ésquisse d'une théorie de la pratique. Paris: Librairie Droz; 1972.

4. Chacón L. La mujer prostituta, cuerpo de suciedad, fermento de muerte: reflexiones en torno a algunos rituales de purificación. Cienc Soc 1992; 58:23-34.

5. [CLAVES] Centro Latino-Americano de Estudo de Violência e Saúde "Jorge Careli". Prostituição infantil feminina: significado e encaminhamento do problema. Rio de Janeiro: CLAVES-FIOCRUZ/OPS; 1994.

6. Gomes R. Prostituição infantil: uma questão de saúde pública. Cad Saúde Pública 1994; 10:58-66.

7. Gomes R. O corpo na rua e o corpo da rua: a prostituição infantil feminina em questão. São Paulo: Unimarco; 1996.
8. Habermas J. Dialética e hermenêutica. Porto Alegre: L\&PM; 1987

9. Madeira FR. Quem mandou nascer mulher? Estudos sobre crianças e adolescentes pobres no Brasil. Rio de Janeiro: Record/Rosa dos Tempos; 1997. A trajetória das meninas dos setores populares: escola, trabalho ou ... reclusão. p. 45-133.

10. Minayo MC de S. O desafio do conhecimento: pesquisa qualitativa em saúde. São Paulo/Rio de Janeiro: Hucitec/ Abrasco; 1992.

11. Rosemberg F. O discurso sobre crianças de rua na década de 80. Cad Pesquisa 1993; 87:71-81.

12- Saffioti H. Exploração sexual de crianças. In: Azevedo MA, Guerra VN de A. Crianças vitimizadas: a síndrome do pequeno poder. São Paulo: Iglu; 1989. p. 49-95. 